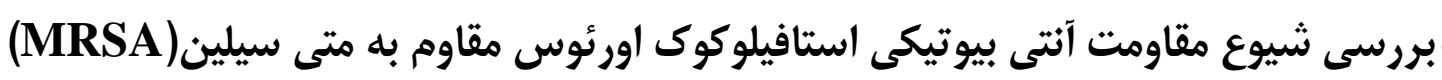

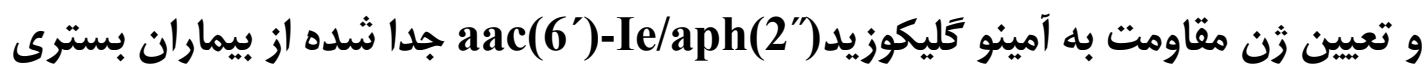

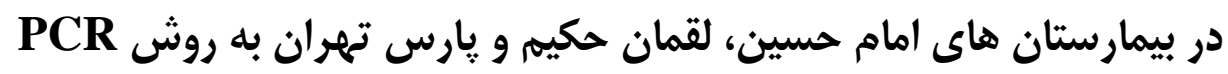

$$
\text { مينا كاوسى'، فهيمه نعمتى منصور "*، سيدمحسن مهليون r }
$$

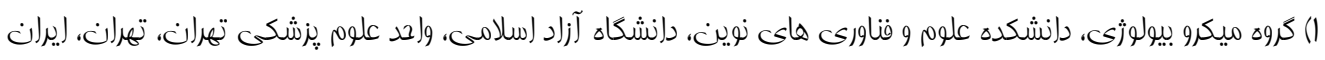

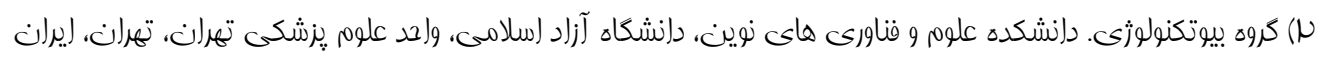

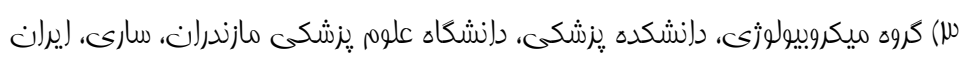

$$
\text { تاريخ دريافت: }
$$

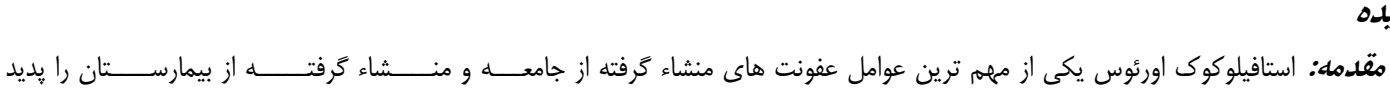

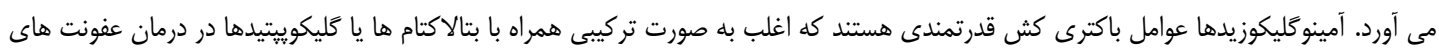

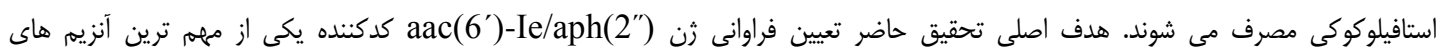

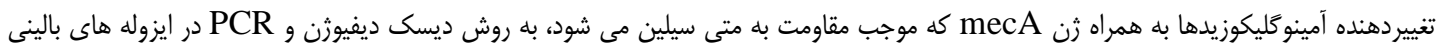
MRSA

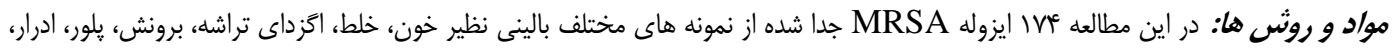

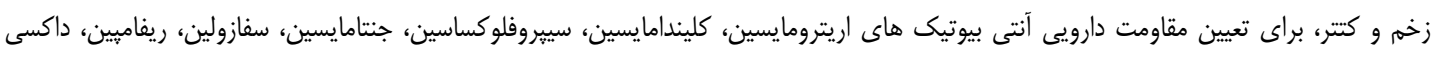

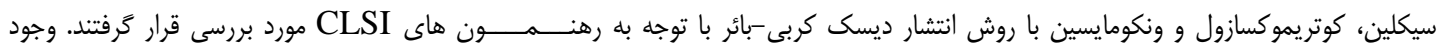

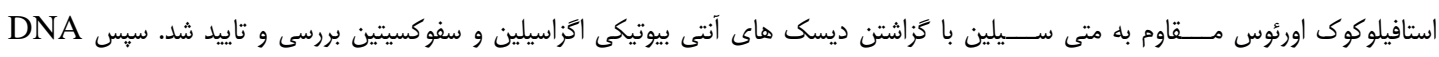

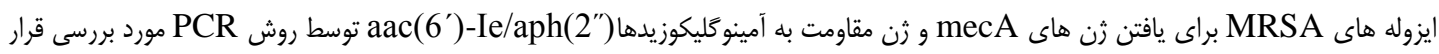

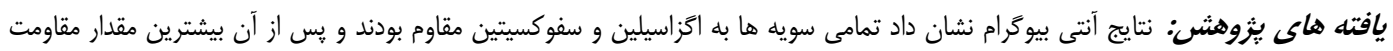

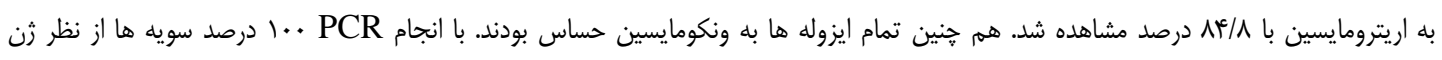
a gecA

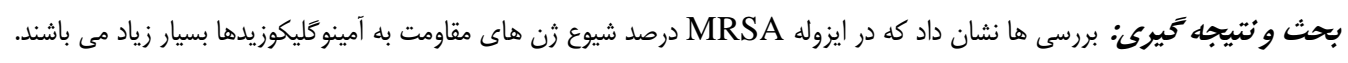

وازه هاى كليدى: زن mecA، آنزيم مقاومت به آمينوكليكوزيدها، استافيلوكوك مقاوم به متى سيلين

* نويسنده مسئول: كروه بيو تكنولوزى. دانشكده علوم و فناورى هاى نوين، دانشكاه آزاد اسلامى، واحد علوم بزشكى تهران، تهران، ايران Email:f_nemati82@yahoo.com

Copyright () 2019 Journal of Ilam University of Medical Science. This is an open-access article distributed under the terms of the Creative Commons Attribution international 4.0 International License (https://creativecommons.org/licenses/by-nc/4.0/) which permits copy and redistribute the material, in any medium or format, provided the original work is properly cited. 
عفونت هاى استافيلوكـــوكى مـــــورد استفـــاده قرار

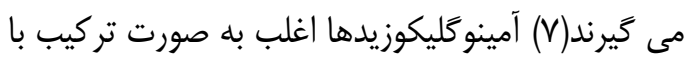

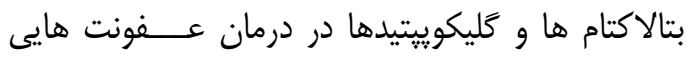

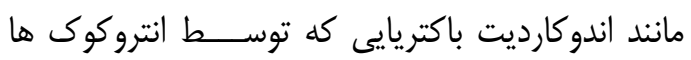

و استافيلوكوك ها ايجاد مى شود كاربرد دارند(^).

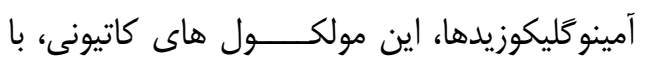

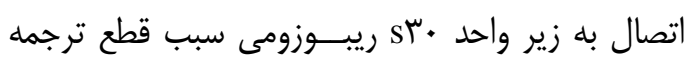

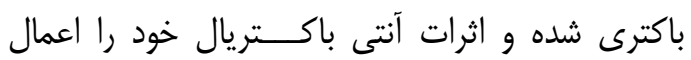
مى كنند(9). سه مكانيسم مقاومت به به آمينو كليكوزيدها

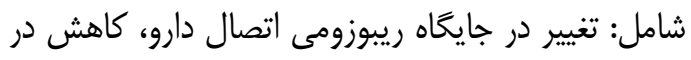

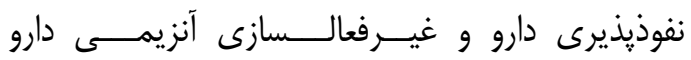

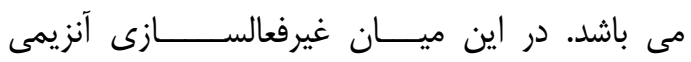

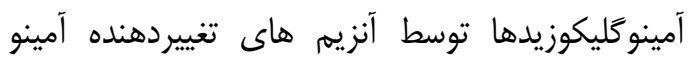
كليكوزيدها اصلى ترين مكانيسم مقاومت در كونه هاى

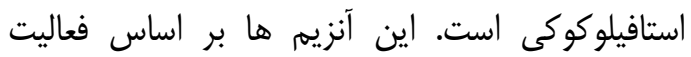

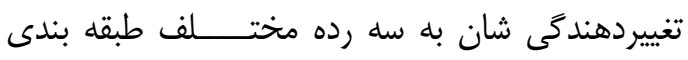

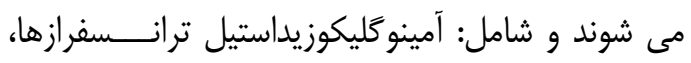

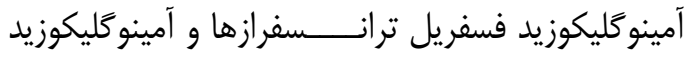

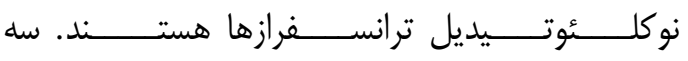

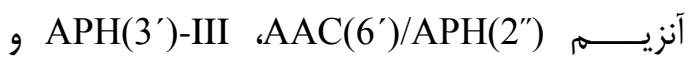
aac(6')- كه به ترتيب توســــــANT(4')

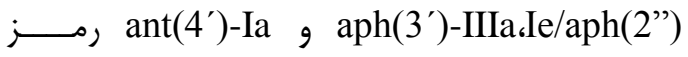
مى شوند جزء شايع ترين آنزيم هاى تغييردهنده در كونه هاى مختلف استافيلوكوى ها هستند و از ازئ اهميت

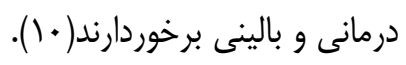

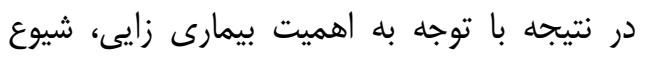

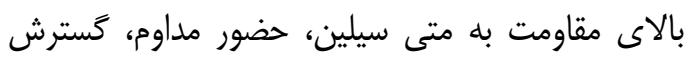
سويه هاى استافيلوكوى اورئوس مقاوم به متى سيل سيلين،

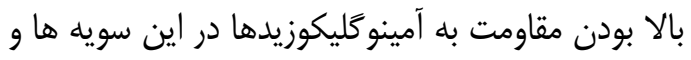

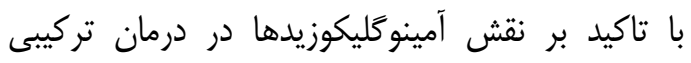

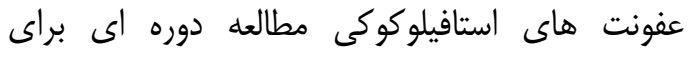

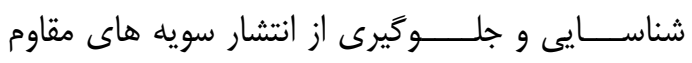

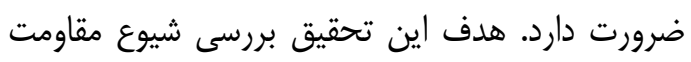

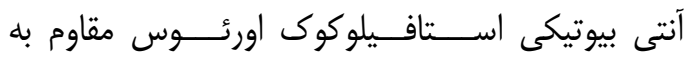

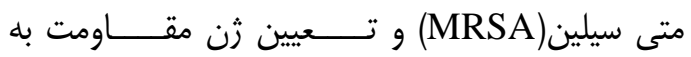

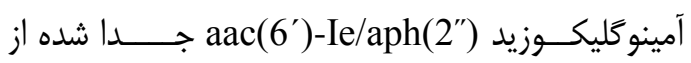
بيماران بسترى در بيمارستان هاى امام حسين، لقمان حكيم و يارس تهران به روش PCR مى بـاشد.
مقدمه

استافيلوكوى اورئوس يكى از مهرم ترين عوامل

عفونت هاى منشاء گرفته از جامعه و منشاء گرفته از

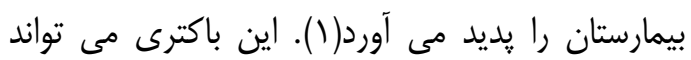

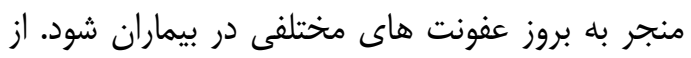

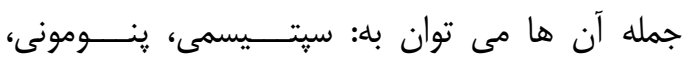

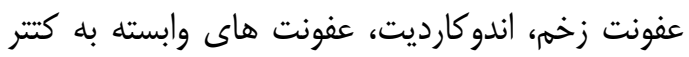
و عفونت مجراى ادرارى(UTI) اشاره نمود(ب). مقاومت به متيسيلين در ايزوله هاى استافيلوكوى اورئوس مقاوم به متى سيلين براى اولين بار در سال

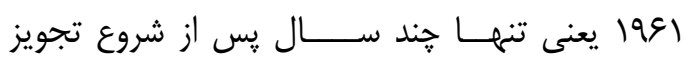

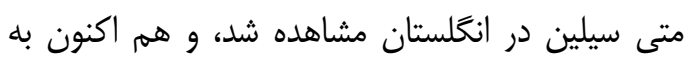

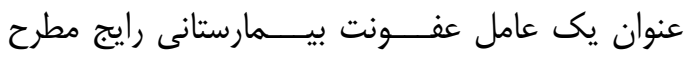

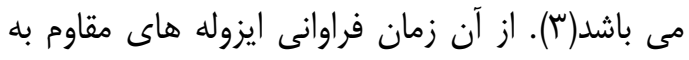

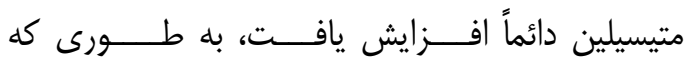

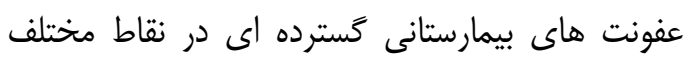

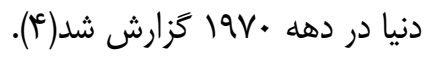
سويه MRSA از استافيلوكوك اورئوس مى بـ باشد

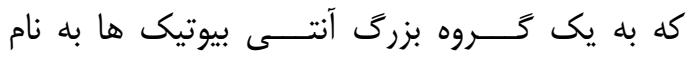

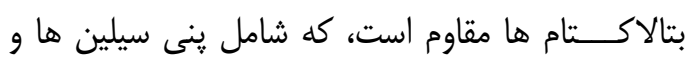

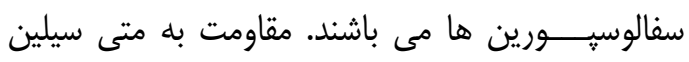

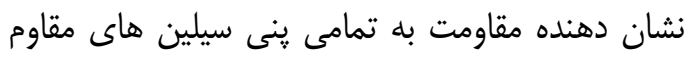

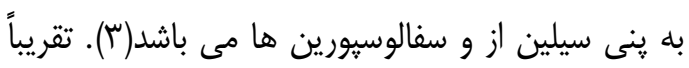

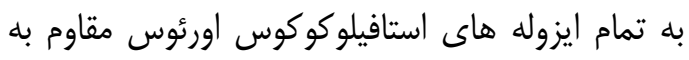
متى سيلين يك يروتئين متصل به ينى سيلين اضافه

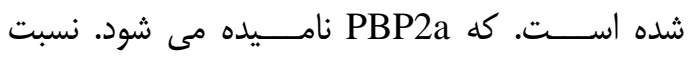
PBP2 بـ PBP2a

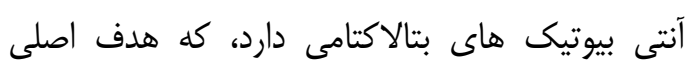

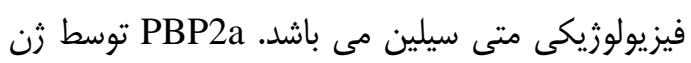
كecA

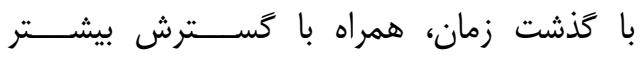

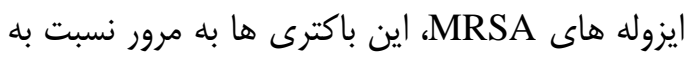
برخى از آنتى بيوتيك هاى ديخر مثل تتراسايكلين ها،

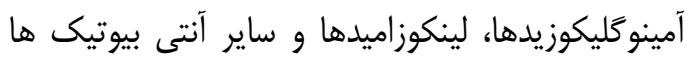
مقاوم شده و درمان عفونت ها را مشكل تر از كذشته لئه

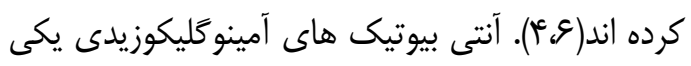

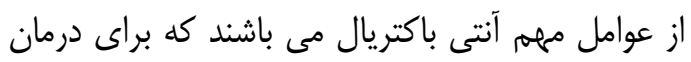

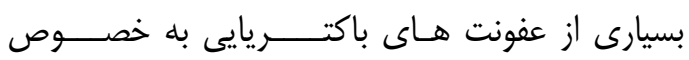




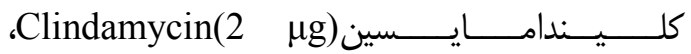

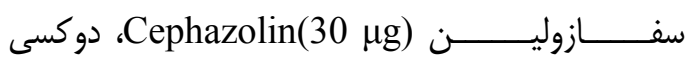

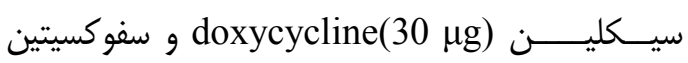
Cefoxitin(30 بg)

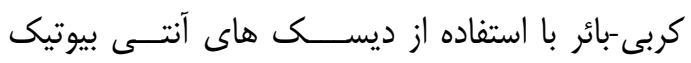
و براى تعيين حساسيت به ونكومايسين (Mast, UK)

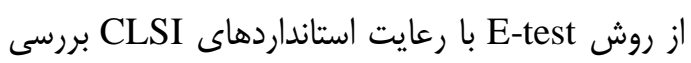

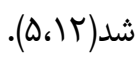

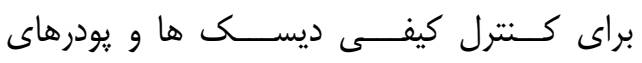

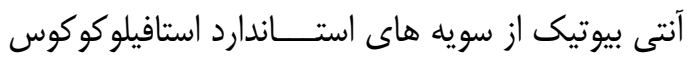

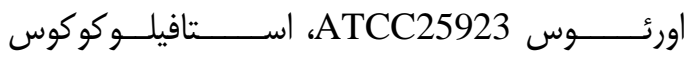
إيبدرميديس ATCC 12228 و انتروكوكوس فكاليس ATCC 29212 استافيلوكوك اورئوس MRSA 400 (تهيه شده از بانكى ميكروبى بيمارستان بوعلى تهران) مقاوم بـ اكزاسيلين براى كنترل مقاومت به اكزاسيلين استفاده

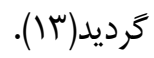
استخراج ثنوم: براى استخراج DNA از سويه هاى

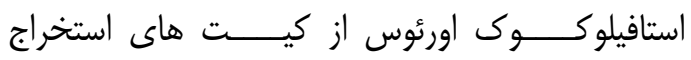
QiaAmp DNA Mini Kit Cat.No: JDNA 51304) شركت كياثن آلمان استفاده شد. مقدارى از

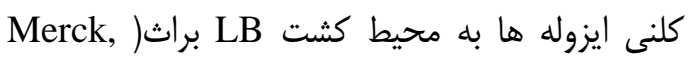
(Germany, Cat Number: 11285

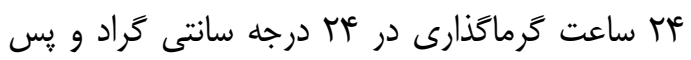

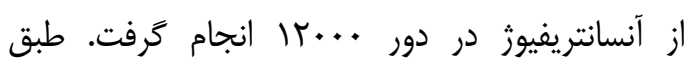

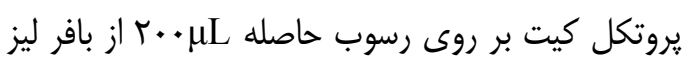

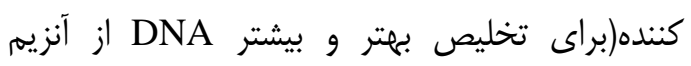
ليزواستافين (Sigma, St Louis, USA) نيز استفاده شد) اضافه و بله مدت ( ساعت در لrّ درجه سانتى كراد

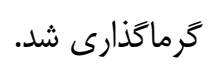

سيــس بروتئيــن كيناز K و و ديكر محلول هاى

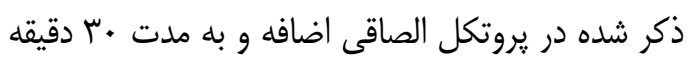

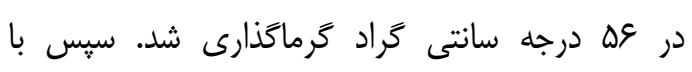
افزودن اتانول مطلق سرد و سانتريفوز آن و اضافه سران

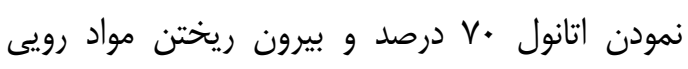
استخراج شده رسوب كرد. سيس بافر حل كننده

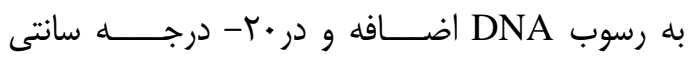

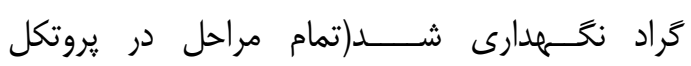

\section{مواد و روش ها}

جمع آورى و تشخيص باكترى ها: در يكى مطالعه

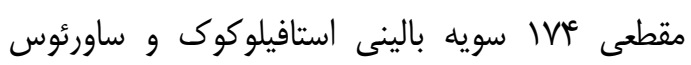

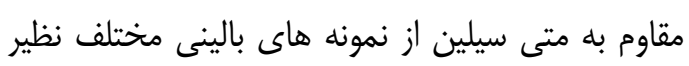

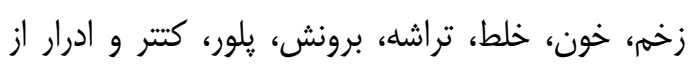

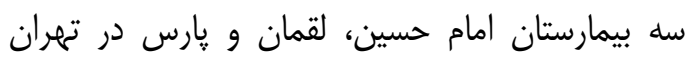

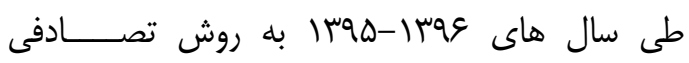

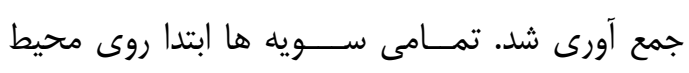

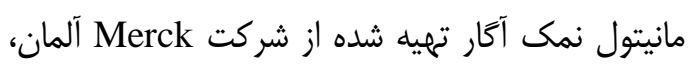

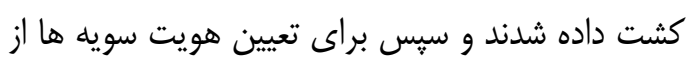

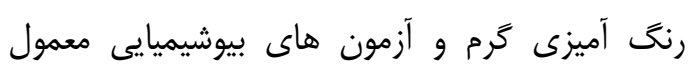

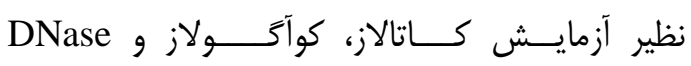
براى تشخيص استافيلوكوى و ساورئوس استفاده شد(1).

در نهايت از تمامى سويه ها در محيط ترييتيك

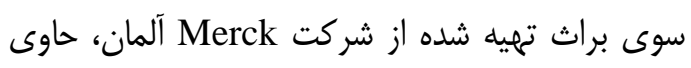
ها درصد كليسرولاستوك كشت ذخيره تهييه و در دران دماى •V- درجه سانتى گراد نتحهدارى شد.

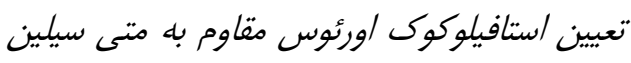

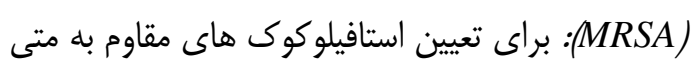
سيلين ابتدا از روش انتشار ديسك بر روى آكار استفاده

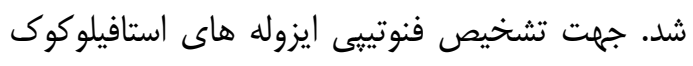

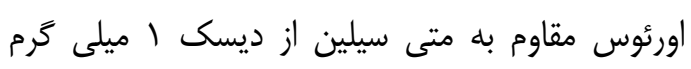

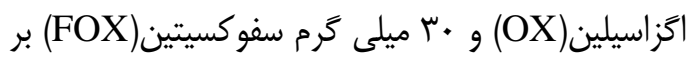
روى محيط مولر هينتون آكار داراى عأ درصد

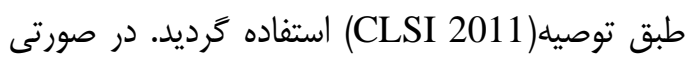

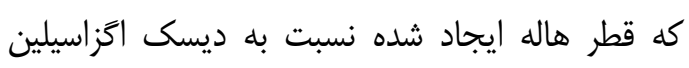

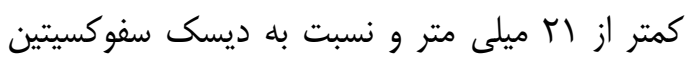

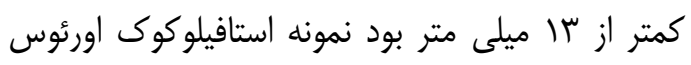

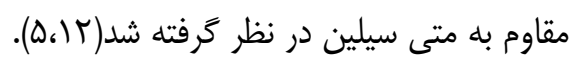
تعيين حساسيت آنتى بيوتيكى سويه ها: براى تعيين

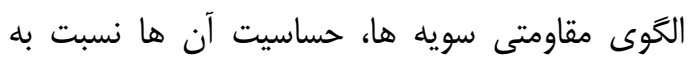

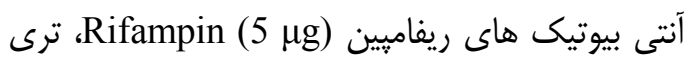

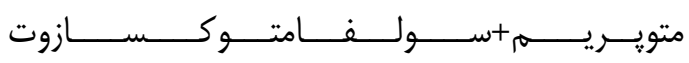
،(trimethoprim+Sulfamethoxazote) $(30 \mu \mathrm{g})$

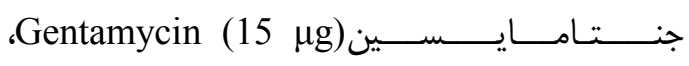

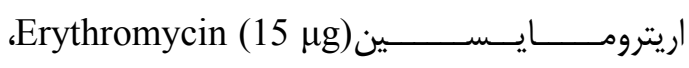

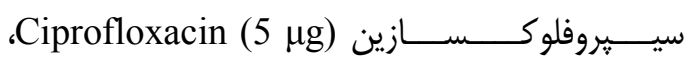


انجام شد(ه). براى اطمينان از درست بودن كار در آزمايش هاى PCR و الكتروفورز از نمونه استاندارد ATCC25923 بله عنوان كنترل مثبت براى سويه استافيلوكوى اورئوس و هم جنين از نمونه استاندارد

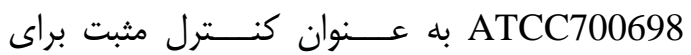
سويه هاى MRSA استفاده شد(أI)(شكل شماره ().
الصاقى درون كيت به طور كامل توضيح داده شده

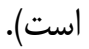
تاييد ثنتيكى /يزوله ها: براى تاييد استافيلوكوى مقاوم به متى سيلين، بررسى تمام ايزله ها از نظر وجود زن mecA و با استفاده از يك جفت يرايمر اختصاصى برسى

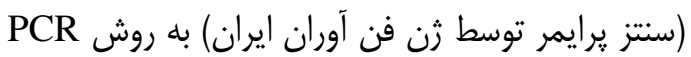

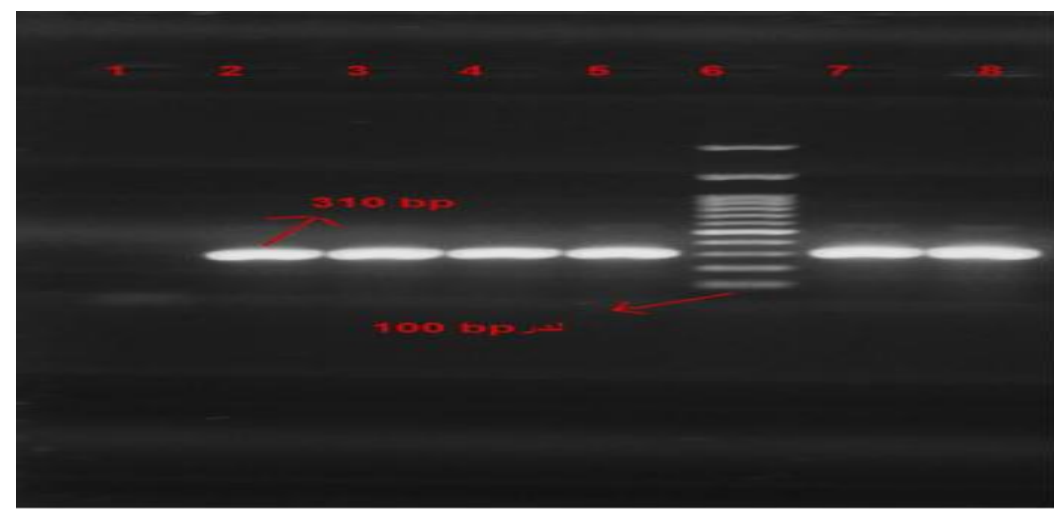

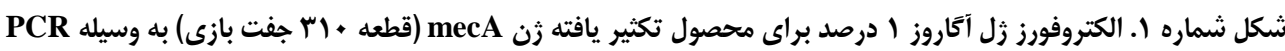

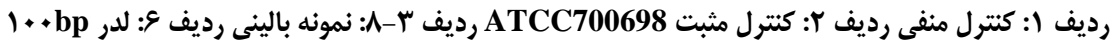

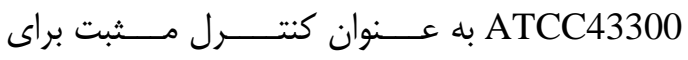
واكنش PCR براى PRSA MR ايزوله

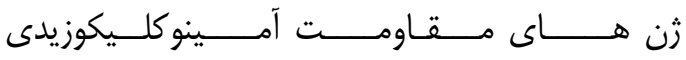

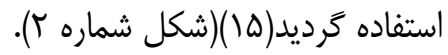

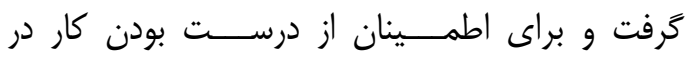
آزمايش هاى PCR و الكتروفورز از نمونه استاندارد

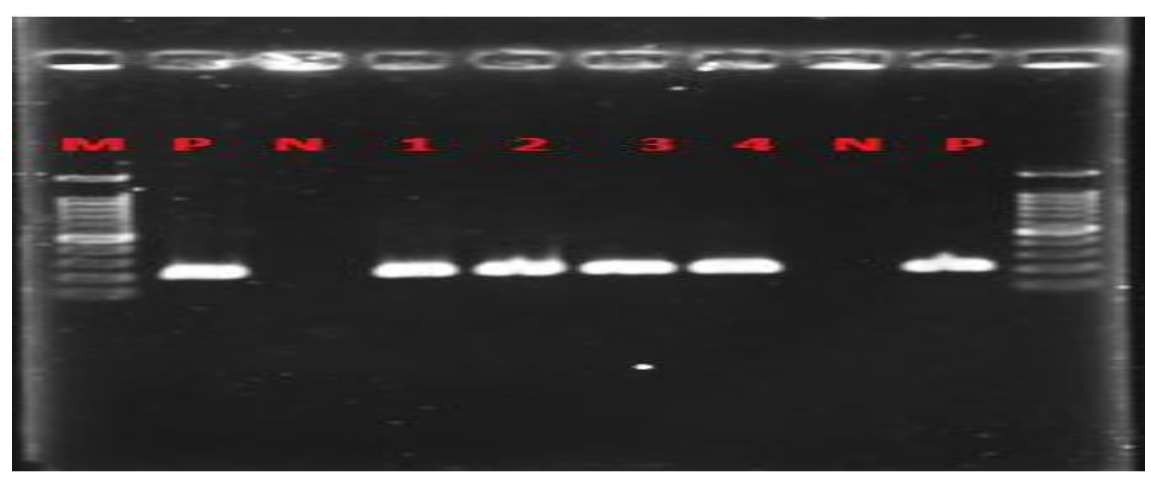

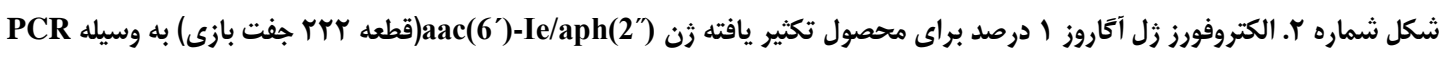

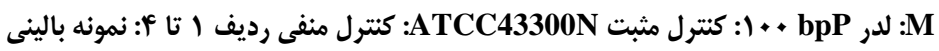

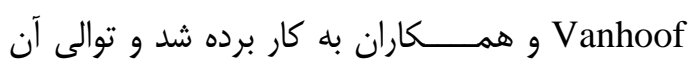

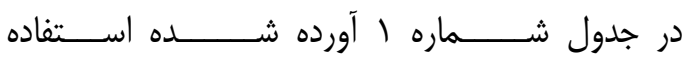

كرديد.
براى تكثير زن (ac(6')-Ie/aph(2"

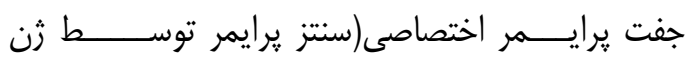

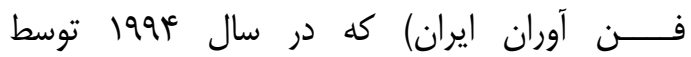


جدول شماره ا. توالى آغازكر هاى مورد استفاده به همراه اندازه محصولات قطعات PCR

\begin{tabular}{|c|c|c|c|}
\hline منابع & سايز & Perimer Sequencimg & Gene \\
\hline (ه) & щ. & $\begin{array}{l}\text { 5'GTAGAAATGACTGAACGTCCGATAA3' } \\
\text { 5'CCAATTCCACATTGTTTCGGTCTAA3' }\end{array}$ & mecA \\
\hline (1) & & $\begin{array}{l}\text { 5'CCAAGAGCAATAAGGGCATACC3' } \\
\text { 5'CACACTATCATAACCACTACCG3' }\end{array}$ & $\operatorname{aac}\left(6^{\prime}\right)-\mathrm{Ie} / \mathrm{aph}\left(2^{\prime \prime}\right)$ \\
\hline
\end{tabular}

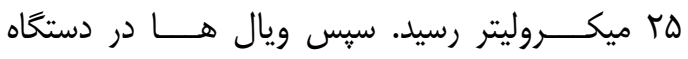

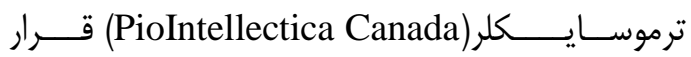
گرفت. برنامه دستخاه ترموسايكلر در جدول شماره r آمده است.
مخلوط نهايى واكنش در حجم

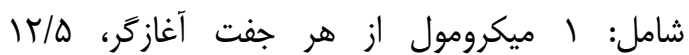
ميكروليتر مسترميكس Amplicon،

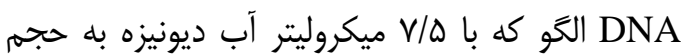

جدول شماره r. مراخل واكنش PCR براى شناسايى ثن هاى مقاومت آمينو مَليكوزيدى و mecA

\begin{tabular}{|c|c|c|c|c|}
\hline فاكتور & \multicolumn{2}{|r|}{ دما ( } & \multicolumn{2}{|r|}{ زمان } \\
\hline 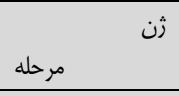 & mecA & $\operatorname{aac}\left(6^{\prime}\right)-\mathrm{Ie} / \mathrm{aph}\left(2^{\prime \prime}\right)$ & mecA & $\operatorname{aac}\left(6^{\prime}\right)-\mathrm{Ie} / \mathrm{aph}\left(2^{\prime \prime}\right)$ \\
\hline واسرشتخى اوليه & $94^{\circ} \mathrm{C}$ & $94^{\circ} \mathrm{C}$ & $5 \mathrm{~min}$ & $5 \mathrm{~min}$ \\
\hline واسرشتخى & $94^{\circ} \mathrm{C}$ & $94^{\circ} \mathrm{C}$ & $1 \mathrm{~min}$ & $1 \mathrm{~min}$ \\
\hline اتصال & $57^{\circ} \mathrm{C}$ & $45^{\circ} \mathrm{C}$ & $1 \mathrm{~min}$ & $1 \mathrm{~min}$ \\
\hline تكثير & $72^{\circ} \mathrm{C}$ & $72^{\circ} \mathrm{C}$ & $30 \mathrm{~s}$ & $30 \mathrm{~s}$ \\
\hline تكثير نهايى & $72^{\circ} \mathrm{C}$ & $72^{\circ} \mathrm{C}$ & $8 \mathrm{~min}$ & $8 \min$ \\
\hline تعداد سيكل & ra & ra & & \\
\hline
\end{tabular}

بررسى قرار گرفتند. نتايج آنتى بيوگرام به روش انتشار يافته هاى يزوهش

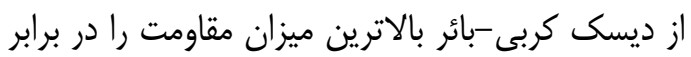
در اين بررسى كه از تير هوسا تا فروردين ماه سال

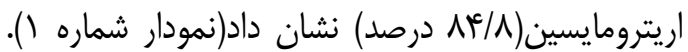

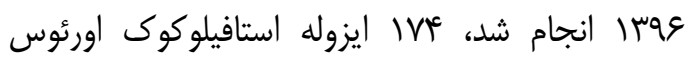

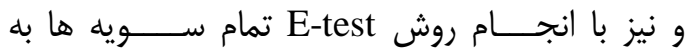
مقاوم به متى سيلين از نمونه هاى مختلف بالينى نظير: ونكومايسين حساس شناخته شدند. هم هنين ميزان

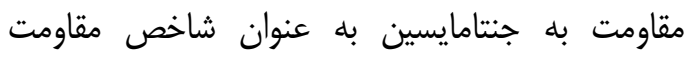
خون(ا/ب درصد)، خلط(T/ا درصد)، اگزداى تراشه

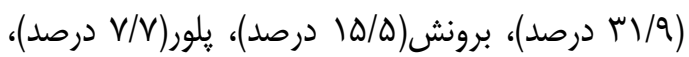

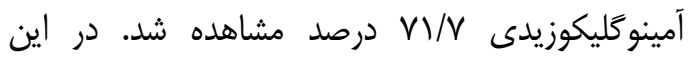

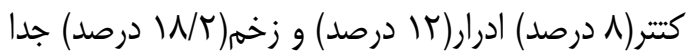
مطالعه ميزان مقاومت جند دارويى نيز بالا بود(جدول شده از بيمارستان هاى امام حسين(V/. د درصد)، لقمان

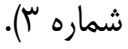

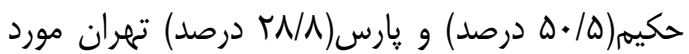

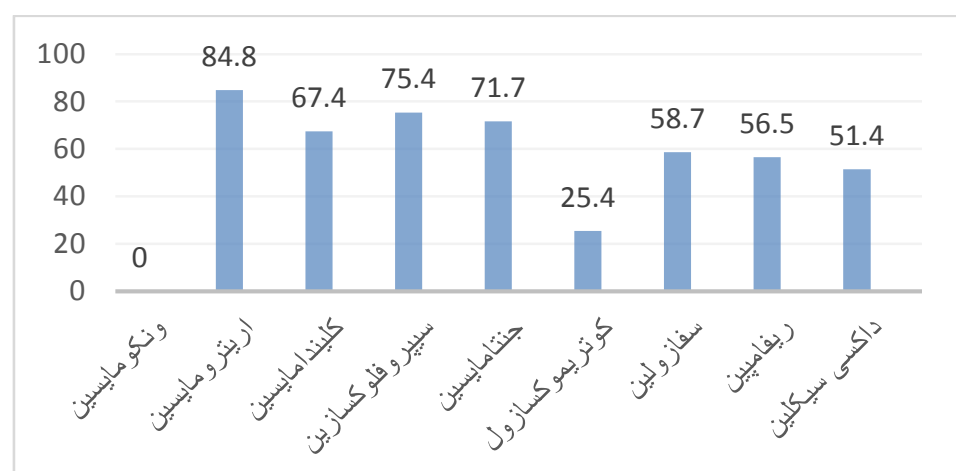

نمودار شماره ا. درصد مقاومت ايزوله هاى استافيلوكوك مقاوم به متى سيلين در برابر آنتى بيوتيك هاى مورد آزمايش 


\begin{tabular}{|c|c|c|c|c|}
\hline امام حسين & بارس & لقمان & درصدكل مقاومت جند كانه & مقاومت حندكانه دارويى \\
\hline$n=r$ & $n=r$ & $n=\omega$ & $\mathrm{n}=9$ & r كلاس آنتى بيوتيكى \\
\hline T/ א درصد & T/K/T درصد & ه ه ه درصد & ا م/1 د درصد & \\
\hline$n=r$ & $n=1$ & $n=r$ & $n=\wedge$ & ז كلاس آنتى بيوتيكى \\
\hline 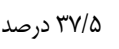 & ه/ ا درصد & ل م مرصد & م/ه أ درصد & \\
\hline$n=a$ & $\mathrm{n}=\mathrm{r}$ & $\mathrm{n}=\mathrm{r}$ & $n=19$ & ه كلاس آنتى بيوتيكى \\
\hline س/ & | | |عץ درصد & | | | & 9/• ا درصد & \\
\hline$n=11$ & $\mathrm{n}=19$ & $n=r$ & $n=q^{c} r$ & צ كلاس آنتى بيوتيكى \\
\hline א & F F ت درصد & ه/ ه د درصد & 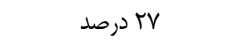 & \\
\hline$n=10$ & $n=r f$ & $n=r r$ & $\mathrm{n}=99$ & Vلاس آنتى بيوتيكى Vل \\
\hline ا & س/عץ درصد & أل درصد & & \\
\hline
\end{tabular}

حساســـيت نشـــان دادند داراى زن mecA بودند.

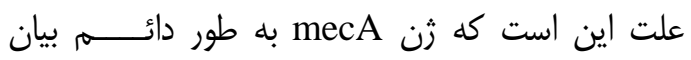

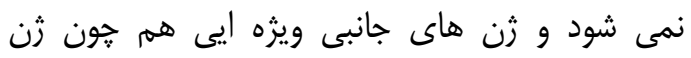
mecR g femA

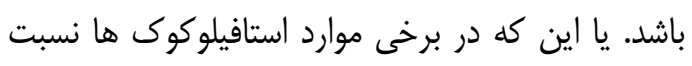

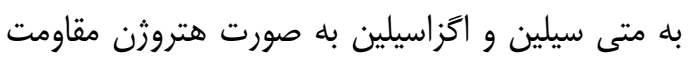
نشان مى دهد و در اين حالت در آزمايش هاى تعيين

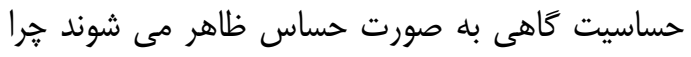

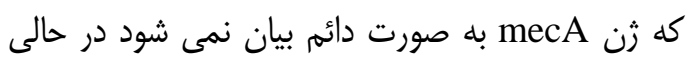

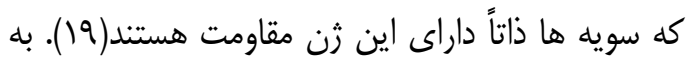
همين دليل است كه از روش PCR به عنوان استاندارد

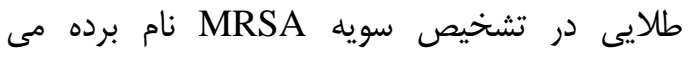

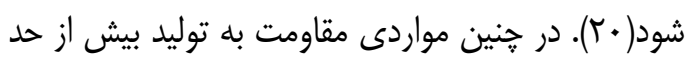

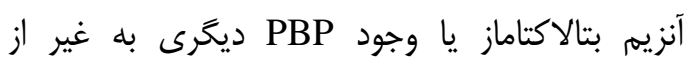

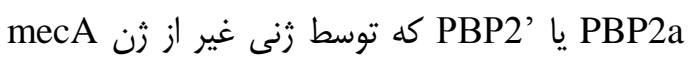

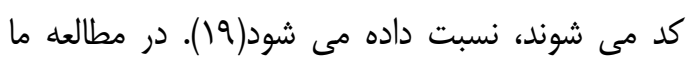

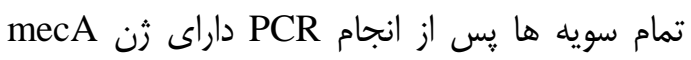

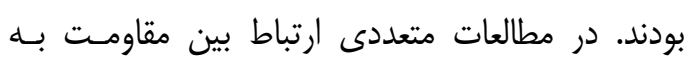

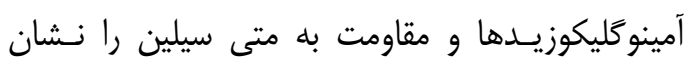

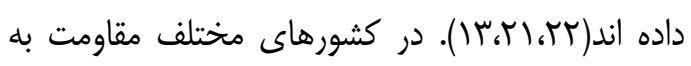

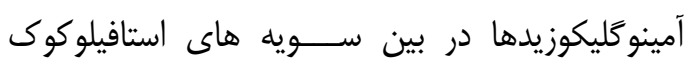

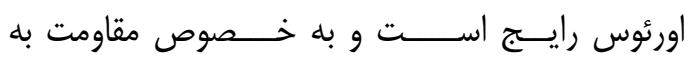
جنتامايسين داراى اهميت كلينيكى بالايى مى ائى باشد. همجنين حساسيت ايزوله هاى استافيلوكوى اورئوس

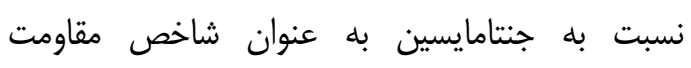

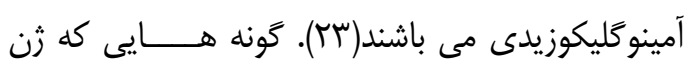
ا ا نكَمهارى مى كردند كدكننده aac(6')-Ia/aph(2')

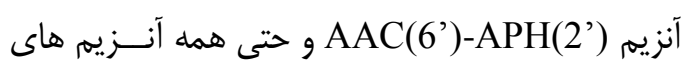

در اين مطالعه با استفاده از تكنيك مولكولى PCR،

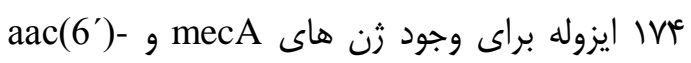
مورد بررسى قرار كرفتند. تمامى ايزوله ها

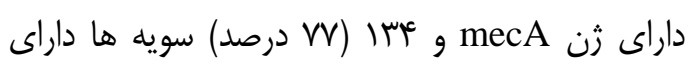
زن ("aac(6')-Ie/aph(2 بودند(نمودار شماره r). بحث و نتيجه كيرى

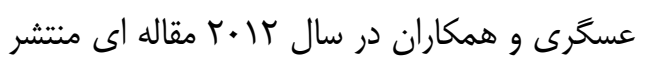

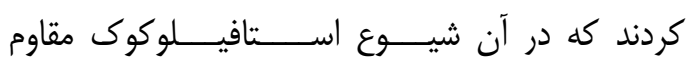
به متى سيلين را در كل مقالات منتشر شده در ايران

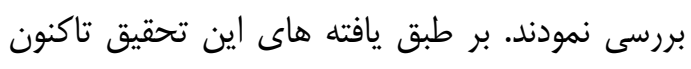

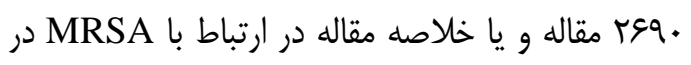

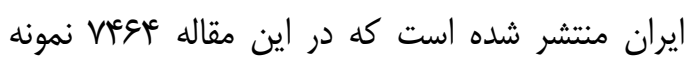

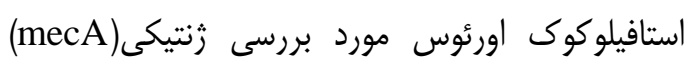

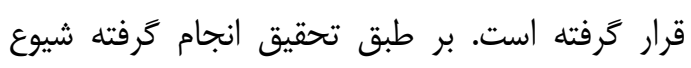
از · MRSA

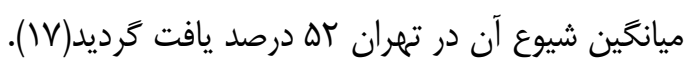

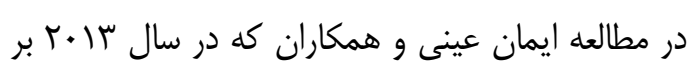

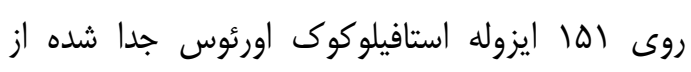

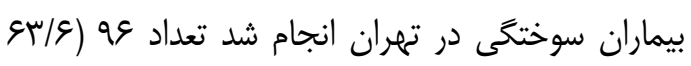

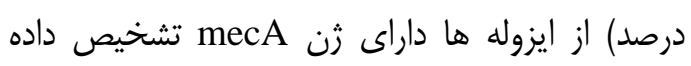

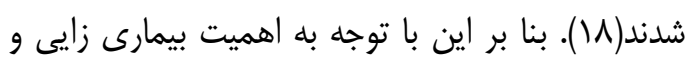

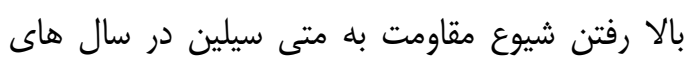

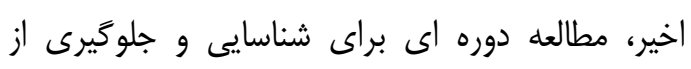

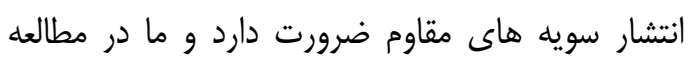

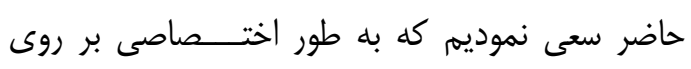
سويه هاى مقاوم به متى سيلين تحقيق نماييه.

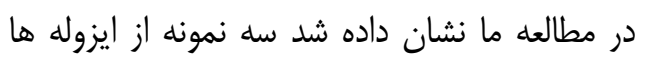
كه در روش ديسك ديفوزن اخزاسيلين و سفوكسيتين 
و N Aph(IIIa) درصد بود(צץ). مطالعه اى كه عباس يادكار و همكاران در سال AMسا بر روى ..1

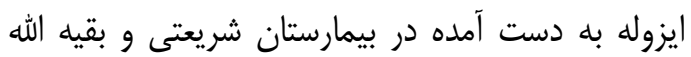

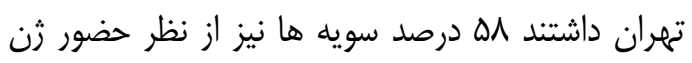

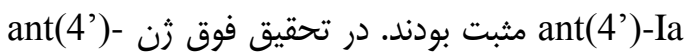

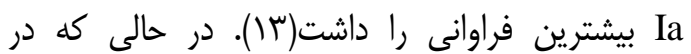

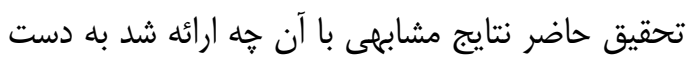

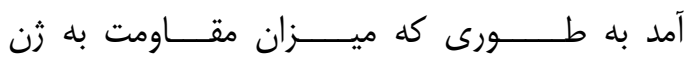
aac(6')/aph(2")-Ia

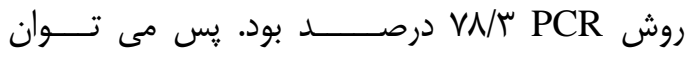
نتيجه كيرى كرد زن هاى مختلف ايجادكننده مقاومت

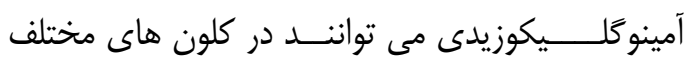

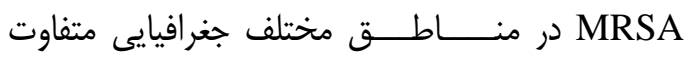

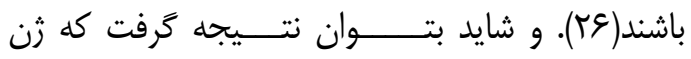
ميزان مـــقاومت آمينو حليكوزيدى 'aac(6')/aph(2')

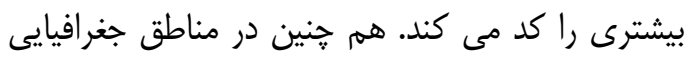

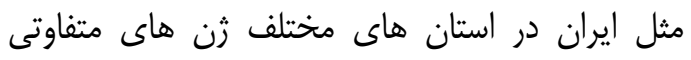
ممكن است علت بروز اين مقاومت باشند و مى تواند

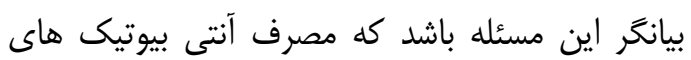

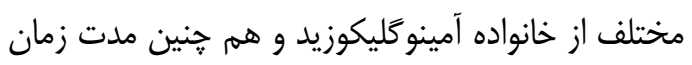

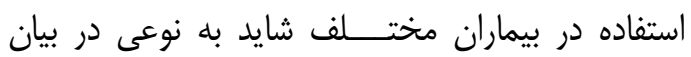
مقاومت موثر باشد.

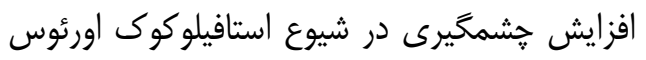

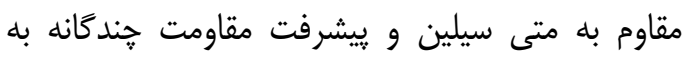

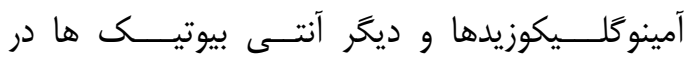
اين سويه ها در سطح جهان مشاهده شده است. در اين

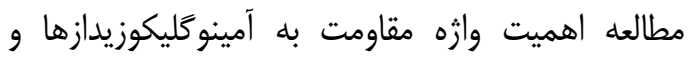
ظهور مقاومت به متى سيلين نشان داده شده و اما واله سرعت و شيوع ييشرفت مقاومت، وابسته بله نحوه

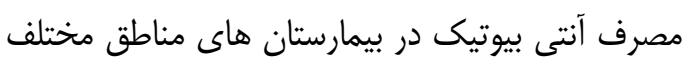
است. در نتيجه سرعت تشخيص عفونت وابسته به

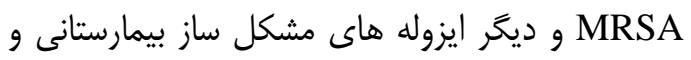

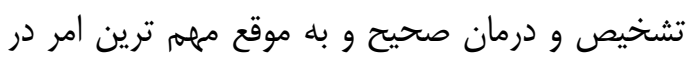

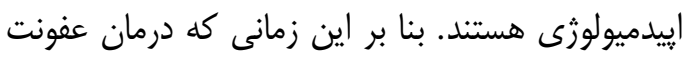
MRSA

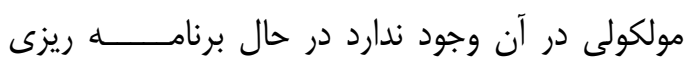

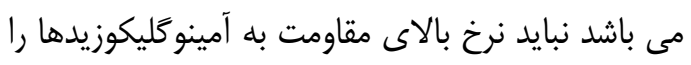

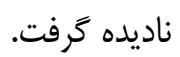

تغيير دهنده آمينوكليكوزيدها به خاطر مقاومت به

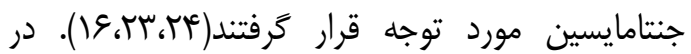

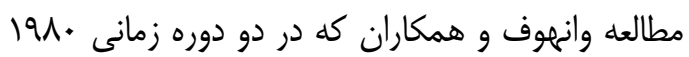

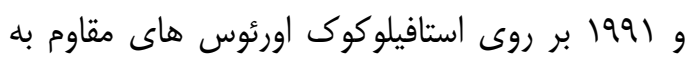
متى سيلين انجام گرفت ميزان مقاومت به جنتافئامكايسين

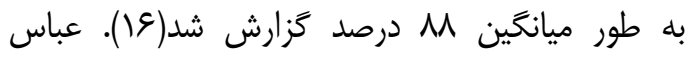

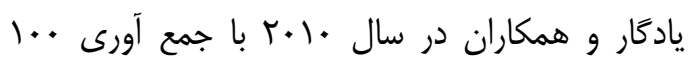

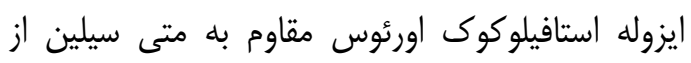
بيمارستان هاى بقيه الله و شريعتى تهران ميزان

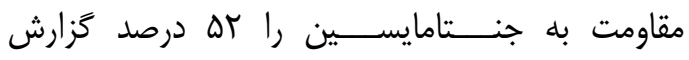

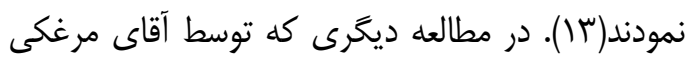

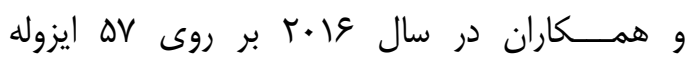

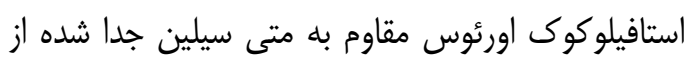

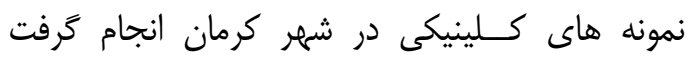

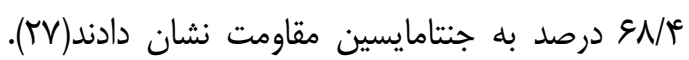

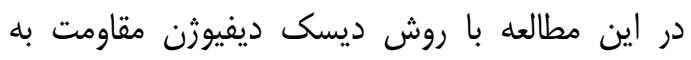

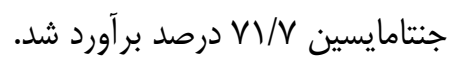
نتايج مطالعات مختلف در ساير كشورها نشان داد درواد

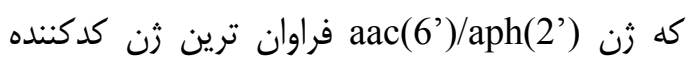
آنزيم هاى AME در ايزوله هاى بالينى (')

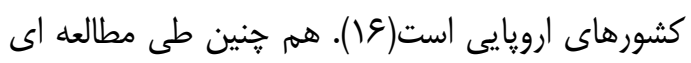

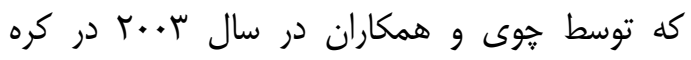

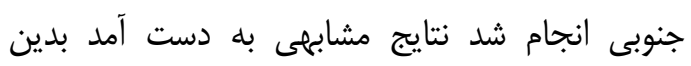

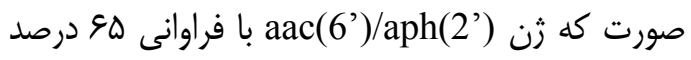
شايع ترين زن در ميان ايزوله هاى مورد مطالعه بود و

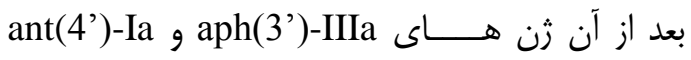

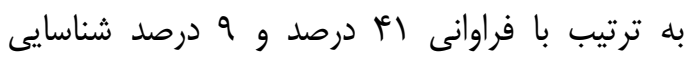

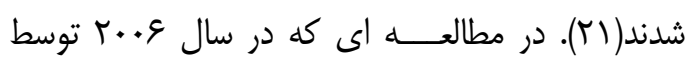
Nurittin aac(6')/Aph(2”) ارئوس هاى مقاوم به متى سيلين مشاهده شد به دنبال

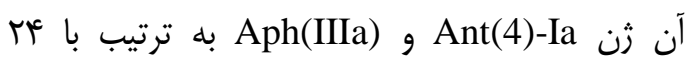

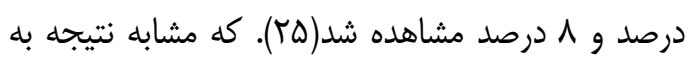

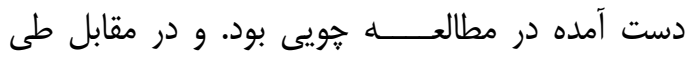

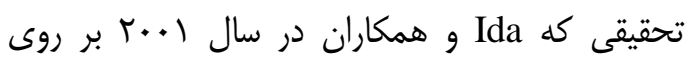

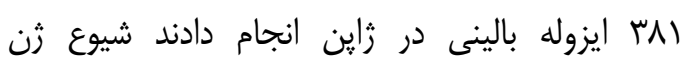
دو Ant(4)-Ia

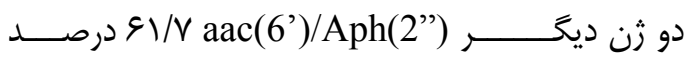




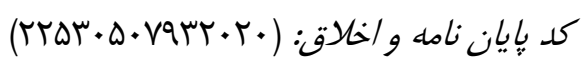

\section{References}

1. Alkhulaifi M, Amin A, Ali A. Phage typing PCR amplification for mecA gene and antibiotic resistance patterns as epidemiologic markers in nosocomial outbreaks of methicillin resistant Staphylococcus aureus. Saudi J Biol Sci2009;

$16: 37-$

49.doi: 10.1016/j.sjbs.2009.07.006

2. Hu Y, Liu A, Vaudrey J, Vaiciunaite B, Moigboi C, Mctavish S, et al. Combinations of $\beta$-lactam or aminoglycoside antibiotics with plectasin are synergistic against methicillin sensitive and methicillin resistant Staphylococcus aureus. PLos One 2015; 10:117664.doi: 10.1371/journal.pone.0117664.

3. Manju M, Ragunathan L, Gautam S. Detection of Methicillin Resistance in Staphylococcus aureus by polymerase chain reaction and conventional methods. J Lab Phys2012; 4:83-88. doi: 10.4103/09742727.105587

4. Moon JS, Lee AR, Kang HM, Lee ES, Kim MN, Palk YH, et al. Phenotypic and genotypic antibiogram of methicillin resistant Staphylococcus aureus isolated from bovine mastitis in Korea. J Dairy Sci 2007; 90:1176-85.

5. Mostafa S. Molecular typing of methicillin resistant Staphylococcus aureus by spa gene polymorphism. AJMR 2013 26; 7:755-9. doi: 10.5897/AJMR12.1430

6. Yinduo JI. Methicillin resistant Staphylococcus aureus protocols. Meth Mol Biol 2007; 391:7.

7. Neeta G, Mohiuddin Q. Rrcent trend of aminoglycoside resistance among Staphylococcus aureus isolate in tertiary care hospital. JMA2014; 6:94-6. doi: 10.5897/JMA2014.0315.

8. Edson R, Terrell C. The aminoglycosides. Mayo Clin Proc1991;66:1158-64.doi: 10.1016/S00256196(12)65798-X.

9. Schmitz F, Fluit C, Gondolf M, Beyrau $\mathrm{R}$, Lindenlauf E, Verhoef J. The prevalence of aminoglycoside resistance and corresponding resistance genes in clinical isolates of staphylococci from 19 European hospitals. J Antimicrob Chemother1999; 43:253-9. doi:10.1093/jac/43.2.253.
10. Oyebode A, Terry A, Olusoga D, Bamigboye K, Animasaun D, Oluremi A. Distribution of genes encoding aminoglycoside modifying enzymes amongst methicillin resistant and methicillin sensitive Staphylococcus aureus isolates from Nigerian hospitals. AJMR 2015; 9:318-25. doi: 10.5897/AJMR2014.7300.

11.Hadadi A, Moraditabriz H, Mehdipour B, Moslehi B, Esmaielzadeh P. [Determining the prevalence of methicillinand vancomycin resistant Staphylococcus aureus by MIC and E-Test]. TUMS J 2011; 69, 344-51. 8.(Persian)

12. Clinical Laboratory Standards Institute. Performance standards for antimicrobial susceptibility testing twenty first informational supplement. CLSI 2011;31:100-21.

13. Yadegar A, Satri M, Mozafari N, GudarziGh. [Pervalence ant 4Ia gene among nosocomial methicillin resistant Staphylococcus aureus by multiplex-PCR]. J Med Sci Modares2010;12,1:59-68. (Persian)

14. Martineau F, Picard FJ, Roy PH, Ouellette M, Bergeron MG. Species specific and ubiquitous- DNA-based assays for rapid identification of Staphylococcus aureus. J Clin Microbiol 1998; 36:618-23.

15. Ardic N, Sareyyupoglu B, Ozyurt M, Haznedaroglu $\mathrm{T}$, Ilga $\mathrm{U}$. Investigation of aminoglycoside modifying enzyme genes in methicillin resistant Staphylococci. Microbiol Res 2006;161:49-54. doi:10.1016/j.micres.2005.05.002.

16. Vanhoof R, Godard C, Content J, Nyssen $\mathrm{H}$, Eleonora $\mathrm{H}$. Detection by polymerase chain reaction of genes encoding aminoglycoside modifying enzymes in methicillin resistant Staphylococcus aureus isolates of epidemic phage types. J Med Microbio1 1994; 28290.doi: 10.1099/00222615-41-4-282.

17. Askari E, Soleymani F, Arianpoor A, Tabatabai SM, Amini A, Naderinasab M. [Epidemiology of mecA methicillin resistant Staphylococcus aureus in Iran]. Iran J Bas Med Sci 2012; 15:1010-19. (Persian) 
18. Emaneini M, Bigverdi R, Kalantar D, Soroush S, Jabalameli F, Noorazarkhoshgnab B, et al. [distribution of genes encoding tetracyclinresistante and aminoglycoside modifying enzymes in Staphylococcus aureuse strains isolatedfrom a burn center]. Ann Burns Fire Dis 2013;26:76-80. (Persian)

19. Sabath LD. Mechanisms of resistance to betalactam antibiotics in strains of Staphylococcus aureus. Ann Int Med 1982; 97: 339-344.

20. Zembower TR, Noskin GA, Postelnick MJ, Nguyen C, Peterson LR. The utility of aminoglycosides in an era of emerging drug resistance. Int $\mathbf{J}$ Antimicrob Age 1998;10:95-105.doi: 10.1016/S09248579(98)00033-8.

21. Choi SM, Kim SH, Kim HJ, Lee DG, Choi JH, Yoo JH, et al. Multiplex PCR for the Detection of genes encoding aminoglycoside modifying enzymes and methicillin resistance among Staphylococcus species. J Korean Med Sci 2003;18:631-6.

doi:

10.3346/jkms.2003.18.5.631.

22. Shaw KJ, Rather PN, Hare RS, Miller $\mathrm{GH}$. Molecular genetics of aminoglycoside resistance genes and familial relationships of the aminoglycoside modifying enzymes. Microbiol Rev 1993;57:138-63.

23. Ounissi H, Derlot E, Carlier C, Courvalin P. Gene homogeneity for aminoglycoside-modifying enzymes in gram positive cocci. Antimicrob Age Chemother 1990; 34:2164-8. doi: 10.1128/AAC.34.11.2164.

24. Udo EE, Dashti AA. Detection of genes encoding aminoglycoside- modifying enzymes in staphylococci by polymerase chain reaction and dot blot hybridization. Int J Antimicrob Agent 2000; 13:273-279. doi: 10.1016/S0924-8579(99)00124-7.

25.Nurittin A, Baris S, Ozyurt M, Haznedaroglu T, Ilga U. Investigation of aminoglycoside modifying enzyme genes in methicillin resistant staphylococci. Microbiol Res 2006; 161:49-54. doi:10.1016/j.micres.2005.05.002.

26. Ida T, Okamoto R, Shimauchi C, Okubo $\mathrm{T}$, Kuga $\mathrm{A}$, Inoue $\mathrm{M}$. Identification of aminoglycoside modifying enzymes by susceptibility testing epidemiology of methicillin resistant Staphylococcus aureus in Japan. J Clin Microbiol 2001;39:311521.doi: 10.1128/JCM.39.9.3115-3121.2001. 27. Marghaki F, Hosseininave H, Kalantarneyestanaki D, Safaari F, Fasihi Y, Moradi M. [Frequency of aminoglycosideresistance genes in methicillin resistnt Staphylococcus aureus isolated from clinical specimens]. J Mazandaran Uni Med Sci 2017; 27: 112-17. (Persian)

\section{The Prevalence of Antibiotic Resistance in Methicillin-Resistant Staphylococcus aureus and the Determination of Aminoglycoside Resistance Gene aac(6')-Ie/aph (2") Isolated from Hospitalized Patientsin Imam Hossein, Loghman Hakim, and Pars Hospitals in Tehran using}




\title{
Polymerase chain Reaction
}

\author{
Kavusi $M^{1}$, Nematimansour $F^{2 *}$, Mahdiyoun $M^{3}$
}

(Received: June 17, 2017

Accepted: February 12, 2018)

\begin{abstract}
Introduction: Staphylococcus aureus is one of the critical pathogens resulted in hospital land community-acquired infections. Aminoglycosides are potent bactericidal agents that are often used in staphylococcal infection treatment in combination with a beta-lactam or glycopeptide antibiotics. The aim of this study was to determine the frequency of encoding gene ofaac (6')Ie/aph (2"). This gene is one of the important aminoglycoside modifying enzymes in combination with mecA which results in methicillin resistance. In doing so, disk diffusion and polymerase chain reaction (PCR) methods were utilized in clinical isolates of methicillin resistant staphylococcus aureus (MRSA).
\end{abstract}

Materials \& Methods: In the current study, 174 clinical isolates of MRSA were obtained from different clinical specimens, including blood, sputum, trachea, brunch, pleura, urine, wound, and catheter. Antibiotic resistance of erythromycin, clindamycin, ciprofloxacin, gentamicin, cefazolin, rifampicin, doxycycline, cotrimoxazole and vancomycin was determined using Kirby-Bauer disk diffusion test method according to the CLSI guidelines. The presence of MRSA was confirmed using oxacillin and cefoxitin anti biotic disc diffusion. Subsequently, DNA of MRSA isolates was investigated to detect mecA and aminoglycoside resistance aac (6')-Ie/aph (2") genes using PCR. Ethics code: 22530507932020

Findings: The results obtained from biogram anti-microbial susceptibility test system indicated that all of the isolates were resistant to oxacillin and cefoxitin. All of the isolates were sensitive to vancomycin and majority of them were resistant to erythromycin $(84.8 \%)$. According to PCR test results, 100 and $78.3 \%$ of the isolates were positive for the mecA and $\operatorname{aac}\left(6^{\prime}\right) / \operatorname{aph}\left(2^{\prime \prime}\right)$-Ia genes, respectively.

Discussion \& Conclusions: According to the results, the aminoglycoside resistance geneswere highly prevalent in MRSA isolates.

Keywords: $\operatorname{aac}\left(6^{\prime}\right)-\operatorname{Ie} / \operatorname{aph}\left(2^{\prime \prime}\right)$, Aminoglycoside modifying enzyme, mecA, Methicillin resistant Staphylococcus aureus

1. Dept of Microbiology, Faculty of Advanced Sciences and Technology, Islamic Azad University, Tehran Medical Sciences Branch, Tehran, Iran

2. Dept of Biotechnology, Faculty of Advanced Sciences and Technology, Islamic Azad University, Tehran Medical Sciences Branch, Tehran, Iran

3. Dept of Microbiology, Faculty of Medicine, Mazandaran University of Medical Sciences, Sari, Iran

*Corresponding author Email: $f \_n e m a t i 82 @ y a h o o . c o m$

Scientific Journal of Ilam University of Medical Sciences 